\title{
Assessment of Physicochemical Properties and Comparison of Dissolution Profiles of Metformin Hydrochloride Tablets in Saudi Arabia
}

\author{
Mohammed Al Bratty ${ }^{1 *}$, Hassan A. Alhazmi ${ }^{1,2}$, Md Shamsher Alam¹, Md Intakhab Alam³, Sadique A. \\ Javed $^{1}$, and Nawazish Alam ${ }^{4}$ \\ ${ }^{1}$ Department of Pharmaceutical Chemistry, College of Pharmacy, Jazan University, Jazan, Saudi Arabia. \\ ${ }^{2}$ Substance Abuse Research Centre, Jazan University, Jazan, Saudi Arabia. \\ ${ }^{3}$ Department of Pharmaceutics, College of Pharmacy, Jazan University, Jazan, Saudi Arabia. \\ ${ }^{4}$ Department of Clinical Pharmacy, College of Pharmacy, Jazan University, Saudi Arabia. \\ e-mail: malbratty@jazanu.edu.sa
}

\section{ABSTRACT}

Although prevalence of substandard or counterfeit drugs is a world-wide problem, poor and developing countries are affected the most. To be a quality product, drug formulation must comply with certain standards. Consequently, in this study, metformin hydrochloride (MH) tablets $(500 \mathrm{mg}$ ) available in the Saudi Arabian market were assessed through various pharmacopeial quality control tests. Parameters including weight variation, hardness, friability, drug content, and disintegration time were evaluated. Results were within acceptable limits for all selected products (nine generic and an innovator). Fourier-transform infrared spectroscopy (FT-IR) spectra of $\mathrm{MH}$ for all tested products were completely superimposed with that of the pure drug, confirming the use of correct active ingredient in all tablet formulations. The products were also evaluated by comparing the dissolution profile of the generic products with the innovator brand in $\mathrm{pH} 6.8$ phosphate buffer. The range of percent drug release in 30 min was $82.71-98.43 \%$, in comparison to $91.86 \%$ for reference product, which complies with the USP-NF specification of at least $80 \%$ drug release in 30 min. The difference factor $\left(f_{1}\right)$, similarity factor $\left(f_{2}\right.$, except product $\left.H\right)$, and dissolution efficiency revealed that the dissolution profiles of the tested products were comparable to that of the reference product. These results show that the tested generic products were biopharmaceutically similar (except product $\mathrm{H}$ ) to the innovator formulation. Therefore, the consumer can select any one of these equivalent products as a substitute for innovator product in case of cost concern or unavailability.

KEYWORDS: Metformin hydrochloride, dissolution study, disintegration test, generic

\section{INTRODUCTION}

$\mathrm{M}$ etformin hydrochloride $(\mathrm{MH})$ is biguanides class drug that is orally administered as a first-line medication used to control blood glucose in type-2 diabetes $(1,2)$. It is a prescription medication approved by the United States Food and Drug Administration (US FDA). The anti-hyperglycemic action is attributed to increase in insulin sensitivity, peripheral use of glucose, along with reduction in glucose production by the liver and intestinal glucose absorption $(1,3)$. Metformin lowers the risk of cardiovascular complications and heart attack by controlling the blood sugar level. Moreover, it improves endothelial function, hemostasis, oxidative stress, insulin resistance, lipid profile, and fat redistribution $(1,4-8)$.

Generic medicines are produced after the patent protection of innovator product is over and made available in markets with different names, which are claimed to be chemically and biopharmaceutically equivalent to the innovator product (9). Generic drugs are significantly useful to decrease the cost of healthcare; however, sometimes the quality of medication has been compromised, mainly in products manufactured in poor and developing counties. There are certain cases of identification of counterfeit and substandard drugs, where the quality of these products does not meet the pharmaceutical standards; as a result, such products may be ineffective or even harmful for the consumers $(10,11)$. Counterfeit drugs may be a drug product with inadequate or without active ingredient, wrong ingredients, and correct active ingredient with fake packaging (12). As per the World Health Organization (WHO), the counterfeit 
drug's share in the global pharmaceutical market is approximately $10 \%$, which is estimated to be increased to $25 \%$ in developing countries and may increase to $50 \%$ in certain poor countries. The FDA has reported that in poor countries, approximately $25 \%$ of drugs available for the consumers are either substandard or counterfeit drugs (10). Moreover, according to WHO, the annual trade from fake medicines are about 73 billion Euros (13). The FDA, WHO, and other concerned organizations such as the Saudi Food and Drug Authority in Saudi Arabia are making continuous efforts to control counterfeit medicines worldwide.

A pharmaceutical product must fulfill certain standards to qualify as a quality drug. To ensure the quality of the available generic products, there are various parameters that must be examined during the manufacturing processes as well as throughout the shelf-life of the product at regular intervals. Several tests are used to evaluate the physicochemical features of drug formulations, such as weight variation, friability, hardness, and content of the active ingredient, whereas the drug release pattern from tablet dosage forms is tested through disintegration and dissolution studies (14). It is well known that, prior to absorption into the systemic circulation, a drug must be in solution, which means a dosage form must efficiently release the drug in the gastrointestinal tract for effective absorption into the systemic circulation. Consequently, in vitro dissolution testing is one of the most crucial steps for understanding the rate and extent of drug release inside the body (15). To reduce the cost of health expenses, WHO favors the substitution of the innovator product with generic ones, provided there is enough evidence supporting that the products are bioequivalent and are of acceptable quality. Comparative in vitro bioequivalence between innovator and generic products is established through the abovementioned quality tests, which are the prerequisites for the marketing authorization of generic formulations (16). Administration of non-bioequivalent generic products may result in alteration in the pharmacokinetic profile of the drug, leading to subtherapeutic drug concentration at the site of action and insignificant therapeutic action $(17,18)$. Dissolution testing has been considered as an indicator for identification of bioavailability-related problems (19). Recently, the application of in vitro dissolution testing has been significantly amplified, as it could replace the in vivo bioequivalence study for some active pharmaceutical ingredients (APIs) (20).

As an effort to minimize the prevalence of substandard and counterfeit medicines, the present study was aimed to evaluate the quality of various brands of $\mathrm{MH}$ tablets (500 $\mathrm{mg}$ ) that are commercially available in the Saudi Arabian market and compare the dissolution profiles in phosphate buffer ( $\mathrm{pH} 6.8$ ) with the innovator product. We hope that the present study will provide scientific basis for consumers to select an appropriate generic substitute for the innovator tablet formulation of $\mathrm{MH}$, especially in case of non-availability or cost concern.

\section{MATERIALS AND METHODS}

The innovator tablet formulation (Glucophage, Merck Sante, Lyon, France), coded as Brand $A$, and nine generic products, coded as Brand B-J, each containing $500 \mathrm{mg}$ $\mathrm{MH}$ were procured from community pharmacies of Jazan, Saudi Arabia. Generic tablet brands B-J included: Formit (SPIMACO, Buraydah, Saudi Arabia), Metfor (Tabuk Pharmaceuticals, Riyadh, Saudi Arabia), Dialon (Julphar, Ras Al Khaimah, UAE), Metaphage (Kuwait Saudi Pharmaceutical Industries Co., Kuwait City, Kuwait), Omformin (National Pharmaceutical Industries, Muscat, Oman), Dimetor (Oman Pharmaceutical Products, Muscat, Oman), Glucare (Jazeera Pharmaceutical Industries, Riyadh, Saudi Arabia), Glymet (Pharma International Co., Amman, Jordan), and Riyadhformin (Riyadh Pharma, Riyadh, Saudi Arabia), respectively. Pure $\mathrm{MH}$ was purchased from Med Chem Express (NJ, USA). Sodium hydroxide pellets, potassium dihydrogen phosphate, methanol, and hydrochloric acid were acquired from Sigma Aldrich (USA). Spectroscopic grade potassium bromide powder was purchased from Thermo Scientific (USA). The chemicals used in this experiment were of analytical grade and used without further purification. The ultra-pure water used in the experiment was produced in-house by using Millipore water purification system (Millipore, France). Microsoft Office 2010, Sigma plot 14.0 software, and Excel 2010 were used for determination of the following parameters: area under dissolution curve (AUC), mean dissolution time, dissolution efficiency (DE), difference factor $\left(f_{1}\right)$, and similarity factor $\left(f_{2}\right)$. The selected generic and innovator products were subjected to weight variation, friability, and hardness tests according to the methods described by the United States Pharmacopeia $(10,21)$.

\section{Extraction and Identification of Active Ingredient}

Five tablets of each product were finely crushed with mortar and pestle and transferred into a beaker. Methanol $(50 \mathrm{~mL})$ was added to the crushed powder and dispersed properly by mechanical shaking. The mixture was sonicated for $15 \mathrm{~min}$ at room temperature and filtered through a Whatman filter grade 1 (GE Healthcare Life Sciences, $150 \mathrm{~mm}$ ). The filtrate was dried 
under vacuum using a rotary evaporator (Stuart, UK). The extracted $\mathrm{MH}$ was identified by Fourier-transform infrared (FT-IR) spectroscopy using a compressed pellet technique. Dried sample (1 $\mathrm{mg})$ was triturated with $100 \mathrm{mg}$ of spectroscopic grade potassium bromide and compressed into a thin transparent pellet with a suitable disc using 10 tons hydraulic pressure. FT-IR spectra of the pellet was recorded by scanning over the transmittance range of $4000-500 \mathrm{~cm}^{-1}$. The procedure was repeated for all tablet brands including the innovator product and pure $\mathrm{MH}$. The spectra from all tablet formulations were compared with that obtained for pure drug.

\section{Determination of Drug Content}

Drug content in each of the selected tablet formulation was determined by performing the assay analysis using the ultraviolet-visible (UV-VIS) spectrophotometer. Pure $\mathrm{MH}(100 \mathrm{mg}$ ) was transferred to a $100 \mathrm{~mL}$ volumetric flask and dissolved in $10 \mathrm{~mL}$ of methanol by sonication, and the volume was made up with phosphate buffer $(\mathrm{pH}$ 6.8). The solution was further diluted to obtain calibration standards solutions having concentrations of $2,4,6,8$, and $10 \mu \mathrm{g} / \mathrm{mL}$. The absorbance values of these solutions were measured at $233 \mathrm{~nm}$, and a calibration plot was constructed using measured absorbance on $y$-axis against the concentration on $x$-axis. The mean weight of 10 tablets from each selected product was determined and crushed into powder. The powder equivalent to $100 \mathrm{mg}$ of $\mathrm{MH}$ was transferred to a $100 \mathrm{~mL}$ volumetric flask and $10 \mathrm{~mL}$ of methanol was added. The mixture was sonicated for $10 \mathrm{~min}$, and final volume was maintained with $\mathrm{pH} 6.8$ phosphate buffer. The mixture was further sonicated for $5 \mathrm{~min}$ and diluted to achieve a target concentration. The solution was filtered with nylon filter $(0.45 \mu \mathrm{m})$ and absorbance was measured at $233 \mathrm{~nm}$. Phosphate buffer (pH 6.8) was used as blank. The procedure was repeated for all the selected tablet brands and drug content per tablet was calculated (22). A result of $100 \% \pm 5 \%$ was considered as acceptable limit.

\section{Disintegration Test}

The disintegration test was performed by using USP disintegration apparatus (basket-rack assembly, Copley Scientific, Nottingham, UK). The test was carried out for all brands included in this study by placing one tablet in each of the six tubes. The tablets were enclosed in a perforated plastic disc to avoid floating on the surface. Each assembly along with the test tablets was placed in $1000-\mathrm{mL}$ vessels containing $900 \mathrm{~mL}$ water maintained at $37 \pm 2{ }^{\circ} \mathrm{C}$. The basket assembly was operated vertically on its axis at a speed of $30 \mathrm{cycle} / \mathrm{min}$ in such a way that the tablets remained $2.5 \mathrm{~cm}$ beneath the surface of the water and $2.5 \mathrm{~cm}$ above the bottom of the vessel during the upward and downward movement of the shaft. Tubes were examined regularly to check for complete disintegration (23).

\section{Dissolution Test}

The dissolution test was performed for innovator tablets and all selected generic tablet brands using USP apparatus 2 (paddle) dissolution apparatus. One tablet was placed in each of the six vessels containing dissolution medium (phosphate buffer $\mathrm{pH} 6.8,900 \mathrm{~mL}$ ) maintained at $37 \pm$ $2{ }^{\circ} \mathrm{C}$. The apparatus was operated at a fixed rotational speed of $50 \mathrm{rpm}$. A sample of $5 \mathrm{~mL}$ from each vessel was withdrawn at fixed time intervals (10 $\mathrm{min}$ ) for $60 \mathrm{~min}$ and was compensated by immediately replacing with fresh dissolution medium after withdrawal. The samples were filtered with a $0.45-\mu \mathrm{m}$ nylon filter and further diluted 100 times with the buffer. The absorbance values of the diluted samples were recorded at $233 \mathrm{~nm}$ using a UV spectrophotometer. The drug released at each time of sampling was calculated from a standard calibration curve prepared by plotting the concentrations of pure $\mathrm{MH}$ in calibration standards against their respective absorbance values. Furthermore, the dissolution profile curve was prepared by plotting percentage release of drug versus time of sample withdrawal. As per USP, the tablets were considered to comply with the standards if at least $80 \%$ of the drug released in $30 \mathrm{~min}(14,24)$. The difference factor $\left(f_{1}\right)$ and similarity factor $\left(f_{2}\right)$ for all generic products were determined with reference to the innovator product. The $f_{1}$ value is the variation between two drug release curves, whereas, $f_{2}$ represents the similarity in the percent drug release between the two dissolution curves at each time point. The values of $f_{1}$ and $f_{2}$ were used to analyze the dissolution profiles of the test products. A generic product with a value of $f_{1}$ between $0-15$ and $f_{2}$ in the range of $50-$ 100 is considered to have a similar drug release profile as the innovator product $(25,26)$.

The drug release is also characterized by DE. It is considered as a non-comparative parameter of dissolution kinetics. $D E$ is defined as the area under the drug dissolution curve (AUC) up to time $t$ (in minutes), expressed as a percentage of the area of the rectangle described by $100 \%$ dissolution of the product label value in the same amount of time (25). The DE for $\mathrm{MH}$ was determined as the ratio of $\mathrm{AUC}_{0 \rightarrow \mathrm{t}}(t$ $=60 \mathrm{~min}$ ) and the total area of the rectangle $\left(T R_{100}\right)$. The area of rectangle was obtained from the multiplication of abscissa $\left(t_{60}=T\right)$ and ordinate $\left(100 \%\right.$ release $\left.=R_{100}\right)$ of release $(\%)$ versus time profile $(25,27)$. 


\section{RESULTS AND DISCUSSION}

The results of weight variation, hardness, friability, and disintegration tests of innovator and generic products of $\mathrm{MH}$ tablets $(500 \mathrm{mg}$ ) are presented in Table 1. Weight variation of the tablet formulation may be due to a variety of reasons and can directly affect the amount of active ingredient in the finished products, which results in poor content uniformity in the dosage forms. To ensure uniform dose, the weight variation among the tablets should be minimum. This may prevent the chance of receiving overdose or underdose tablets, which could result in unpredictable therapeutic effects. The products were considered to pass the weight variation test if the individual weights of not more than 2 tablets (out of 20) were deviated by $\pm 5 \%$ of the average weight. All selected brands of $\mathrm{MH}$ tablets were found to comply with the acceptance criteria and hence, were within the USP-NF specifications.

Differences in tablet hardness among the brands may be due to different properties of the excipients used in the manufacturing processes. Hardness is a measure of the crushing strength of the tablets and may affect the rate of tablet disintegration and drug release. The mean hardness values of the tested generic formulations were in the range of 68.65-177.79 N. The lowest mean hardness $(68.65 \mathrm{~N})$ was recorded for product $\mathrm{B}$, whereas the product $\mathrm{H}$ was able withstand the highest mechanical force $(177.79 \mathrm{~N})$ applied to crush the tablets. However, none of the products, except product B, could satisfy the in-house criteria of 39.23-68.65 N. Results revealed that all products could pass the lower limit, and only one product met the limit of maximum hardness. Friability testing was done to evaluate the capacity of a tablet to withstand abrasion during handling, packaging and transportation. Excess friability of a tablet formulation may result in weight loss, affecting the therapeutic response, in addition to general appearance and patient acceptability. Maximum friability was recorded for product B $(0.363 \%)$, which is most likely to lose particles during handling, while the least friable product was found to be product $D(0.030 \%)$. Overall, the weight loss recorded for all the tested products were below $1 \%$, which complies with USP-NF specifications.

Identification of active ingredient in generic products was established by comparing the FT-IR spectrums with that of the pure $\mathrm{MH}$. The spectra of all products were completely superimposed with that of the pure drug, which confirms the presence of $\mathrm{MH}$ as an active ingredient in all tested tablet formulations. FT-IR spectra of pure $\mathrm{MH}$, the innovator product (brand $A$ ), and the selected generic products (brands B-J) are shown in Figure 1.

Table 1. Weight Variation, Hardness, Friability, and Disintegration Time of Tested Tablets Containing $500 \mathrm{mg} \mathrm{MH}$

\begin{tabular}{|c|c|c|c|c|}
\hline Product & $\begin{array}{c}\text { Weight, } \mathrm{mg} \\
(\boldsymbol{n}=\mathbf{2 0})\end{array}$ & $\begin{array}{c}\text { Hardness, } \\
(n=10)\end{array}$ & $\begin{array}{c}\text { Friability, } \\
(\boldsymbol{n}=10)\end{array}$ & $\begin{array}{c}\text { Disintegration Time, min } \\
(\boldsymbol{n}=6)\end{array}$ \\
\hline A $^{*}$ & $531.34 \pm 6.49$ & $129.45 \pm 3.43$ & $0.038 \pm 0.01$ & $8.24 \pm 0.43$ \\
\hline B & $524.98 \pm 4.62$ & $68.65 \pm 6.54$ & $0.363 \pm 0.03$ & $8.50 \pm 0.21$ \\
\hline C & $545.20 \pm 6.82$ & $94.18 \pm 6.43$ & $0.055 \pm 0.02$ & $6.34 \pm 0.25$ \\
\hline D & $650.81 \pm 9.76$ & $126.01 \pm 5.66$ & $0.030 \pm 0.01$ & $8.05 \pm 0.46$ \\
\hline E & $555.46 \pm 5.40$ & $93.62 \pm 4.28$ & $0.288 \pm 0.07$ & $7.54 \pm 0.38$ \\
\hline F & $600.30 \pm 4.34$ & $125.56 \pm 2.50$ & $0.116 \pm 0.04$ & $7.89 \pm 0.44$ \\
\hline G & $557.64 \pm 3.27$ & $87.00 \pm 2.35$ & $0.079 \pm 0.01$ & $14.45 \pm 0.33$ \\
\hline H & $525.22 \pm 4.86$ & $177.79 \pm 3.32$ & $0.053 \pm 0.02$ & $10.43 \pm 0.52$ \\
\hline I & $589.43 \pm 3.21$ & $85.85 \pm 4.18$ & $0.121 \pm 0.04$ & $9.32 \pm 0.42$ \\
\hline
\end{tabular}

*Innovator brand product. Data are expressed as mean \pm SD. MH, metformin hydrochloride. 


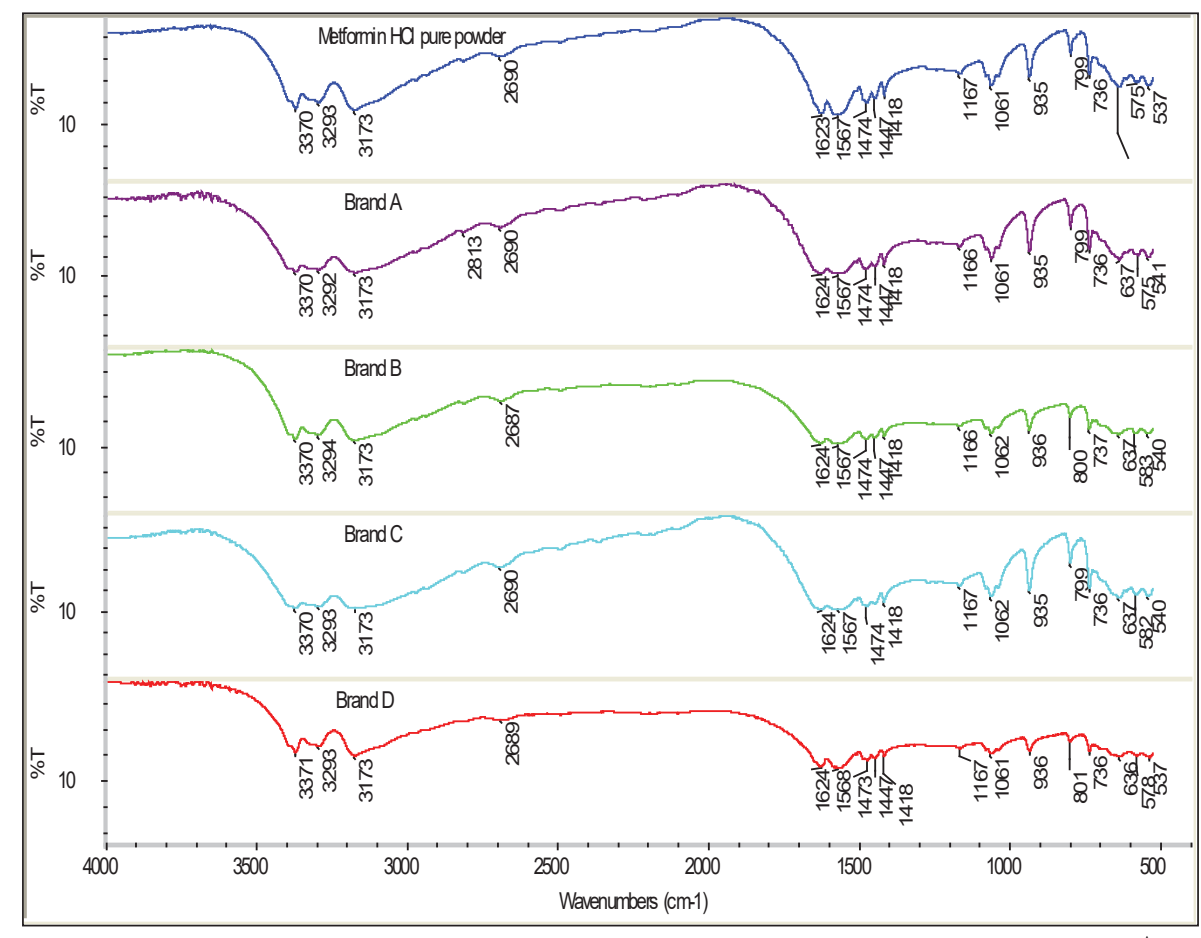

A

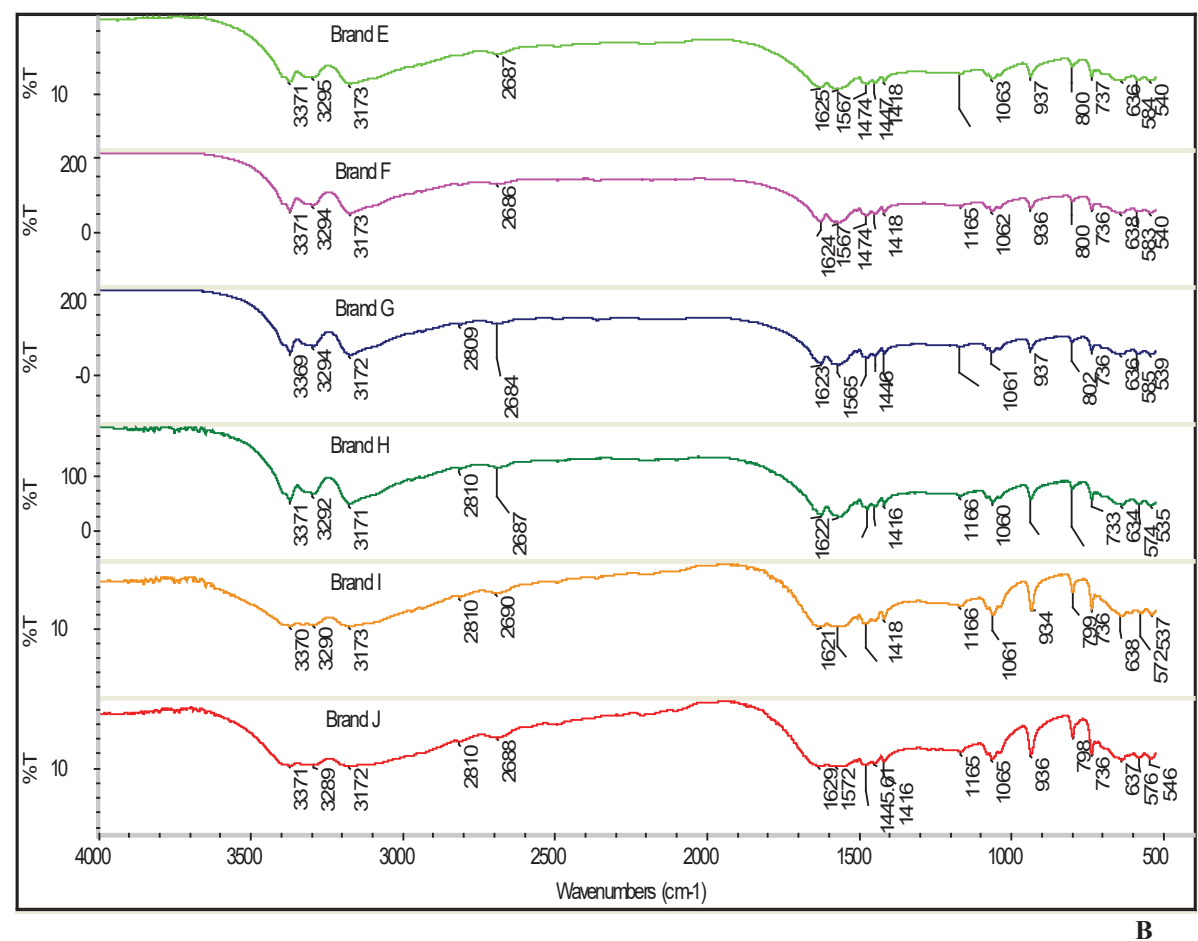

Figure 1. FT-IR spectra of pure $\mathrm{MH}$ and $\mathrm{MH}$ extracted from tablet dosage forms of innovator (brand $A$ ) and test generic brands $(B-D)(A)$ and $(E-J)(B)$. FT-IR: Fourier-transform infrared; $M H$ : metformin hydrochloride. 
The percentage of the drug content for the selected products is shown in Figure 2. The assay results for all products were in the range of $96.52 \%-103.37 \%$, which meets USP-NF acceptance criteria of $100 \pm 5 \%$ per tablet. The amount of drug content was estimated after comparing with calibration curve. The correlation coefficient $\left(R^{2}\right)$ was 0.9999 , and the regression equation was obtained as, $y=0.0809 x+0.0056$. Disintegration time may directly influence the $\mathrm{MH}$ release from tablets and hence, $\mathrm{MH}$ bioavailability in tablet formulations. In this study, all the selected tablet brands passed the disintegration test according to the USP-NF specifications for film coated tablets, as all tablets were completely disintegrated within $30 \mathrm{~min}$ (Table 1). Among the tested products, the fastest disintegration was recorded for product $\mathrm{D}(6.34 \mathrm{~min})$, and product $\mathrm{H}$ exhibited slowest disintegration rate (14.45 $\mathrm{min})$.

\section{Dissolution Profile}

The dissolution profile of a drug product is of extreme importance in predicting the bioavailability and in vivo drug release pattern $(28,29)$. Metformin belongs to Class 3 as per Biopharmaceutics Classification System (BCS) and according to USP specifications, at least $80 \%$ of the drug should be released in $30 \mathrm{~min}$ at $50 \mathrm{rpm}$. The observed dissolution profiles of generic products were compared with the innovator product to examine the pharmaceutical similarity of these products. The percentage of metformin released from the innovator (A) and generic (B-J) formulations at the 30-min time point was: $91.86 \%, 89.37 \%, 91.09 \%, 96.65 \%, 93.91 \%, 98.43 \%$, $82.71 \%, 85.37 \%, 85.89 \%$, and $86.12 \%$, respectively. The dissolution test results revealed that all tested products released more than $80 \%$ of drug at 30 min time point and complied with the USP-NF specifications. Therefore, these products may be considered as pharmaceutically equivalent on the basis of their in vitro drug release profiles. However, the small differences in the drug release from one product to another may be due to the differences in the amount and types of excipients used in the manufacturing process of these formulations (30). The dissolution profiles of all the generic and innovator products is shown in Figure 3. The mean drug content measured for product $\mathrm{F}$ was $96.52 \%$ of the label claim, which is significantly lower than other tested generic formulations (100.66-103.37\%) in this study. However, the drug release of product $\mathrm{H}$ was close to $100 \%$ (98.43\%) in $30 \mathrm{~min}$. The possibility of differences between drug content and release of drug in dissolution test may be explained on the basis of the type of tablets selected for the test. In this study, the tablets were randomly selected for each test. Hence, there is a possibility that the tablets selected for drug content analysis contained less drug than those selected for dissolution study. However, the results of both tests satisfied the acceptance criteria set by USP-NF.

The difference factors $\left(f_{1}\right)$ for all the tested generic products were below 15 and the similarity factors $\left(f_{2}\right)$ were in the range $50-100$, except product $\mathrm{H}\left(f_{2}=43.89\right)$, as shown in Table 2 . The $f_{1}$ and $f_{2}$ values were calculated using the dissolution profile of individual products. These values show that in vitro drug release profiles of the tested products are similar to the innovator product, except product $\mathrm{H}$, which did not achieve the US-FDA recommendation of $f_{2} \geq 50$ (31). Among the tested products, dissolution profiles of products $B$ and $E$ were the most similar to the reference product as these products have exhibited lowest $f_{1}$ (4.08 and 2.47 , respectively) and highest $f_{2}$ values (67.83 and 77.68 , respectively). On the other hand, product $\mathrm{H}$ had the highest $f_{1}$ (12.26) and lowest $f_{2}$ (43.89) values among the tested generic products. The low $f_{2}$ value of product $\mathrm{H}$ suggests that the dissolution profile was not similar to the innovator product; however, product $\mathrm{H}$ did comply with the USP criterion of $\geq 80 \%$ drug release in $30 \mathrm{~min}$.

Determination of the DE is another way to evaluate and compare the drug release pattern from several products. The DE of a product is directly related to the actual amount of active ingredient dissolved in the solution and it provides better prediction of in vivo drug release. Calculation of DE employs area under dissolution curve over a time period. The test products are considered to be similar when their DE values are close to that of reference product (within $\pm 10 \%$ is often acceptable) (26). DE values of all generic products selected in this study ranged from $74.2 \%$ to $88.0 \%$, which were within $\pm 10 \%$ range of the innovator product $(81.4 \%)$, as shown in Table 2 . The highest DE value was recorded for product D (88.0\%), and the lowest value $(74.2 \%)$ was observed for product $\mathrm{H}$. Moreover, mean dissolution time was also estimated to better understand the dissolution profile of the tested products. Mean dissolution time of all tested products was similar to that of innovator product (9.69 $\mathrm{min})$. The product $D$ showed highest value $(10.38 \mathrm{~min})$ and product $\mathrm{H}$ had the lowest value $(8.55 \mathrm{~min})$.

\section{CONCLUSION}

Commercially available immediate-release $\mathrm{MH}$ tablets (500 mg) in the Saudi Arabian market were subjected to several quality control tests. All selected products were found to comply with USP-NF specifications with respect to weight variation, friability, disintegration time, and 


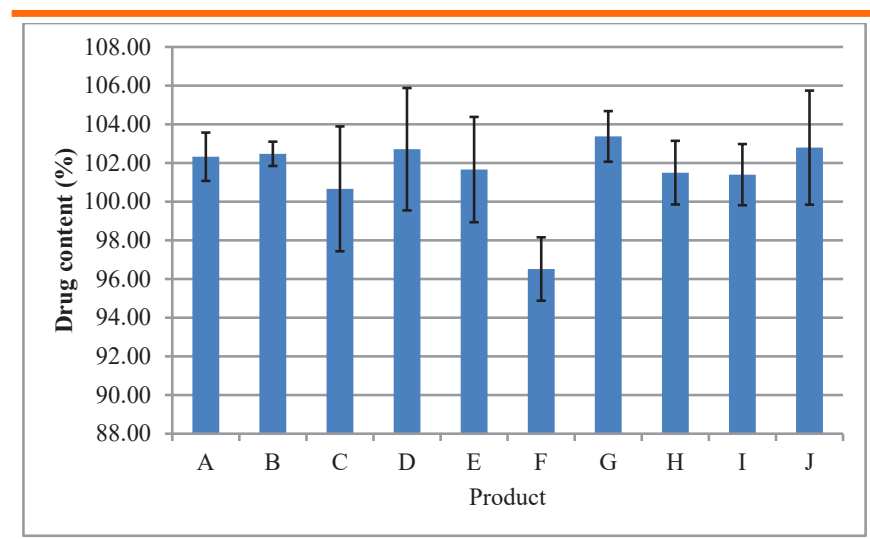

Figure 2. Drug content (mean $\pm S D$ ) of different brands of metformin hydrochloride tablets. Brand $A$ is the innovator product; brands $B-J$ are generic products.

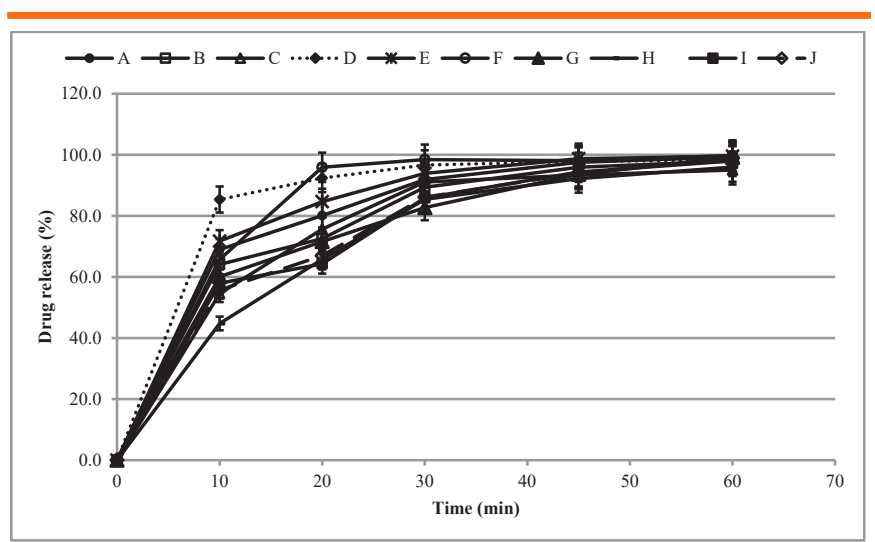

Figure 3. Dissolution profiles (mean $\pm S D$ ) of metformin hydrochloride tablets in phosphate buffer $\mathrm{pH}$ 6.8. Brand A is the innovator product, brands $B-J$ are generic products.

Table 2. Parameters for Drug Release Including of Tested Tablets Containing $500 \mathrm{mg} \mathrm{MH}$

\begin{tabular}{|c|c|c|c|c|c|}
\hline Product & AUC & MDT, $\min$ & DE, \% & Difference factor $\left(f_{1}\right)$ & Similarity factor $\left(f_{2}\right)$ \\
\hline A $^{*}$ & 4846.7 & 9.69 & 81.4 & 0 & 100 \\
\hline B & 4656.9 & 9.31 & 79.2 & 4.08 & 67.83 \\
\hline C & 4553.9 & 9.10 & 79.9 & 6.41 & 56.71 \\
\hline D & 5190.2 & 10.38 & 88.0 & 7.92 & 51.18 \\
\hline E & 4965.4 & 9.93 & 83.1 & 2.47 & 77.68 \\
\hline F & 5065.9 & 10.13 & 84.6 & 6.07 & 55.24 \\
\hline G & 4498.5 & 8.99 & 75.6 & 6.98 & 57.28 \\
\hline H & 4275.4 & 8.55 & 74.2 & 12.26 & 43.89 \\
\hline I & 4446.4 & 8.89 & 75.6 & 8.51 & 51.80 \\
\hline J & 4456.3 & 8.91 & 75.1 & 8.21 & 52.47 \\
\hline
\end{tabular}

*Innovator product. Dissolution medium was phosphate buffer $\mathrm{pH}$ 6.8. MH, metformin hydrochloride; AUC, Area under the dissolution curve; MDT, Mean dissolution time; $D E$, dissolution efficiency.

drug content analysis. The dissolution profile for eight out of nine generic products was similar to that of innovator product and satisfied the USP-NF specifications. $\mathrm{MH}$ release from all tested products in phosphate buffer (pH-6.8) in 30 min was more than $80 \%$ of the labeled claim at $50 \mathrm{rpm}$ paddle speed. Generic products B and $\mathrm{E}$ displayed the most similar dissolution profiles and $\mathrm{DE}$ values in comparison to the innovator product. These two products also had lowest $f_{1}$ and highest $f_{2}$ values. Although generic product $\mathrm{H}$ had an $f_{2}$ value $<50$; it passed dissolution test specifications for USP and exhibited acceptable DE compared to the innovator product. Therefore, all generic products tested are considered to be acceptable substitutes for the innovator brand in case of unavailability and when the cost is a concern. However, in vivo bioequivalence study may be needed for final comment on the similarity of efficacy of these generic formulations.

\section{ACKNOWLEDGMENT}

The authors thank the Deanship of Scientific Research, Jazan University, Jazan, Saudi Arabia, for providing funds to conduct this research (Project No. JUP8//000317).

\section{CONFLICTS OF INTEREST}

The authors disclosed no conflicts of interest related to this article.

\section{REFERENCES}

1. Holman, R. Metformin as first choice in oral diabetes treatment: the UKPDS experience. J. Annu. Diabetol. Hotel. Dieu. 2007, 13-20.

2. Rojas, L. B. A.; Gomes, M.B. Metformin: an old but still the best 
treatment for type 2 diabetes. Diabetol. Metab. Syndr. 2013, 5, 6. DOI: 10.1186/1758-5996-5-6.

3. Wu, T.; Xie, C.; Wu, H.; Jones, K. L.; Horowitz, M.; Rayner, C. $\mathrm{K}$. Metformin reduces the rate of small intestinal glucose absorption in type 2 diabetes. Diabetes. Obes. Metab. 2017, 19, 290-293. DOI: 10.1111/dom.12812.

4. Shishavan, M. H.; Henning, R. H.; Buiten, A.; Goris, M.; Deelman, L. E.; Buikema, H. Metformin improves endothelial function and reduces blood pressure in diabetic spontaneously hypertensive rats independent from glycemia control: Comparison to vildagliptin. Sci. Reports. 2017, 7, 10975-10987. DOI: 10.1038/ s41598-017-11430-7.

5. Ouslimani, N.; Peynet, J.; Bonnefont-Rousselot, D.; Thérond, P.; Legrand, A.; Beaudeux, J. L. Metformin decreases intracellular production of reactive oxygen species in aortic endothelial cells. Metabolism. 2005, 54, 829-834. DOI: 10.1016/j. metabol.2005.01.029.

6. Gran, P. J. Beneficial effects of metformin on haemostasis and vascular function in man. Diabetes Metab. 2003, 29, 6S446S52. DOI: 10.1016/s1262-3636(03)72787-6.

7. Tseng, C. H. Metformin use is associated with a lower risk of hospitalization for hart failure in patients with type 2 diabetes mellitus: a retrospective cohort. J. Am. Heart Assoc. 2019, 8: e011640. doi: 10.1161/JAHA.118.011640.

8. Lin, S. H.; Cheng, P. C.; Tu, S. T.; Hsu, S. R.; Cheng, Y. C.; Liu, Y. $\mathrm{H}$. Effect of metformin monotherapy on serum lipid profile in statin-naïve individuals with newly diagnosed type 2 diabetes mellitus: a cohort study. Peer J. 2018, 6: e4578. doi: 10.7717/ peerj.4578.

9. Danchev, N.; Nikolova, I. Generics - Present and Future. Biotechnol. Biotechnological Equip. 2007, 21, 94-99. DOI: 10.1080/13102818.2007.10817423.

10. Uddin, M. S.; Mamun, A. A.; Hossain, M. S.; Asaduzzaman, M.; Sarwar, M. S.; Rashid, M.; Herrera Calderon, O. In vitro quality evaluation of leading brands of ciprofoxacin tablets available in Bangladesh. BMC Res. Notes. 2017, 10, 185. DOI: 10.1186/ s13104-017-2507-y.

11. Buckley, G. J.; Gostin, L. O. Countering the problem of falsified and substandard drugs. Board on Global Health; Institute of Medicine, Washington (DC): National Academies Press (US), 2013. DOI: $10.17226 / 18272$.

12. Almuzaini, T.; Choonara, I.; Sammons, H. Substandard and counterfeit medicines: a systematic review of the literature. BMJ Open. 2013, 3: e002923. DOI: 10.1136/bmjopen-2013-002923.

13. Beware of Counterfeits: Background Information on Counterfeit Drugs, Bayer Global, December 14, 2018. https://www.bayer. com/en/background-information-on-counterfeit-drugs.aspx.

14. Metformin Hydrochloride Tablets Monograph. In The United States Pharmacopeia. USP29-NF24; The United States Pharmacopeial Convention, Inc.: Rockville, MD, 2007.

15. Azarmi, S.; Roa, W. H., Lobenberg, R. Targeted delivery of nanoparticles for the treatment of lung diseases. Adv. Drug Del.
Rev. 2008, 60, 863-875. DOI: 10.1016/j.addr.2007.11.006.

16. WHO Expert Committee on Specifications for Pharmaceutical Preparations. Multisource (generic) pharmaceutical products: guidelines on registration requirements to establish interchangeability; WHO Technical Report Series, No. 937, Annex 7; World Health Organization: Geneva, 2006; pp 347438. DOI: 10.1002/jps.2600620248.

17. Uddin, M. S.; Mamun, A. A.; Rashid, M.; Assaduzzaman, M. In-process and finished products quality control tests for pharmaceutical capsules according to pharmacopoeias. Br. J. Pharm. Res. 2016, 9, 1-2. DOI: 10.9734/BJPR/2016/22044.

18. Fahmy, S.; Abu-Gharbieh, E. In vitro dissolution and in vivo bioavailability of six brands of ciprofloxacin tablets administered in rabbits and their pharmacokinetic modeling. Biomed. Res. Int. 2014, 1-8. DOI: 10.1155/2014/590848.

19. Shah V. P. Dissolution: a quality control test vs a bioequivalent test. Dissolution Technol. 2001, 8, 1-2. dx.doi.org/10.14227/ DT080401P6.

20. Waiver of In Vivo Bioavailability and Bioequivalence Studies for Immediate-Release Solid Oral Dosage Forms Based on a Biopharmaceutics Classification System; Guidance for Industry; U.S. Department of Health and Human Services, Food and Drug Administration, Center for Drug Evaluation and Research (CDER), U.S. Government Printing Office: Washington, DC, 2000. DOI: 10.1201/9780824741969.axh.

21. Karmakar, P.; Kibria, M. G. In vitro comparative evaluation of quality control parameters between paracetamol and paracetamol/caffeine tablets available in Bangladesh. Int. Curr. Pharm. J. 2012, 1, 103-109. DOI: 10.3329/icpj.v1i5.10282.

22. Gurunath, S.; Shailesh, S.; Narendar, D.; Rani, G.; Sandhya, N.; Baswaraj, K. Strongly enhanced dissolution rate of candesartan cilexetil solid dispersion tablets by incorporation of superdisintegrants. J. Pharm. Res. 2011, 4, 4190-4194.

23. <701> Disintegration. In The United States Pharmacopeia and National Formulary; The United States Pharmacopeial Convention, Inc.: Rockville, MD, 2008.

24. Stuart, A. V.; Clement, Y.; Sealy, P.; Löbenberg, R.; MontaneJaime, L.; Maharaj, R. G.; Maxwell, A. Comparing the dissolution drofiles of seven metformin formulations in simulated intestinal fluid. Dissolution Technol. 2015, 22, 17-21. DOI: 10.14227/ DT220115P17.

25. Costa, P.; Lobo, J. M. S. Modeling and comparison of dissolution profiles. Eur. J. Pharm. Sci. 2001, 13, 123-133.

26. Popy, F. A.; Dewan, I.; Parvin, M. N.; Islam, S. M. A. Evaluation of in vitro equivalence for tablets containing the poorly watersoluble compound atrovastatin. Dissolution Technol. 2012, 19, 30-33. DOI: 10.14227/DT190412P30.

27. Khan, K. A. The concept of dissolution efficiency. J. Pharm. Pharmacol. 1975, 27, 48-49. DOI: 10.1111/j.2042-7158.1975. tb09378.x.

28. Balan, G.; Timmins, P.; Greene, D. S.; Marathe, P. H. In vitro-in vivo 
correlation (IVIVC) models for metformin after administration of modified-release (MR) oral dosage forms to healthy human volunteers. J. Pharm. Sci. 2001, 90, 1176-1185. DOI: 10.1002/ jps.1071.

29. Sweetman, S. C., Ed. Martindale: The Complete Drug Reference, 33rd ed.; Pharmaceutical Press: London; 2002.

30. Block, L. C.; Schemling, L. O.; Couto, A. G.; Mourão, S. C.;
Bresolin, T. M. B. Pharmaceutical equivalence of metformin tablets with various binders. Rev. Cienc. Farm. Basica Apl. 2008, 29, 29-35.

31. Polli, J. E.; Rekhi, S.; Augsburger, L. L.; Shah, V.P. Methods to compare dissolution profiles and a rationale for wide dissolution specifications for metoprolol tartrate tablets. J. Pharm. Sci. 1997, 86, 690-700. DOI: 10.1021/js960473x. 